\title{
EDITORIAL
}

\section{In this Issue: The Patient-Clinician Relationship and Practice-Based Network Research}

\author{
Kurt C. Stange, $M D, P b D$, Editor \\ Ann Fam Med 2004;2:386-387. DOI: 10.1370/afm.234.
}

$\mathrm{P}$ ractice-based research networks (PBRNs) are emerging as the essential laboratory for the generation of new knowledge that is relevant to the types of problems and patients seen in primary care practice. This expanded issue features 9 PBRN studies, which help develop the methods for PBRN research and showcase the involvement of research networks in studies of importance for practice and policy. We are grateful to the American Academy of Family Physicians Foundation for their unrestricted support of publication of the PBRN articles in this expanded issue.

The issue also features a cluster of 4 research studies, 2 essays, and an editorial on the topic of the clinician-patient relationship. Several of these studies investigate the critical topic of continuity of care that was the focus of the September-October 2003 issue of the Annals. Other articles in this issue address important clinical, policy, and methodology topics.

\section{PBRN RESEARCH}

The study by Mold and colleagues in the Oklahoma Physicians Resources/Research Network' disentangles the different factors associated with night sweats, day sweats, and hot flashes in older patients. The findings provide new insights into possible causes for these common complaints and help to guide their clinical evaluation.

In a randomized clinical trial conducted in the AAFP National Network and a network of Missouri practices, Vinson and colleagues compared 2 brief screening instruments for problem drinking. ${ }^{2}$ The findings show the acceptability, likelihood of use, and outcome of these 2 methods of screening.

The Wisconsin Research Network conducted a study led by Beasley and colleagues ${ }^{3}$ related to the basic science of primary care practice. In examining the number of problems addressed by family physicians during outpatient visits, these researchers found a mismatch between the essential primary care functions of prioritizing and integrating care for multiple problems and the current categorical approaches to billing, quality assessment, research, and education. The findings should help us to redesign our thinking, as well as our health care systems.

A study by Pace and colleagues ${ }^{4}$ used data from the National Ambulatory Care Survey to assess the degree to which seasonal variation in diagnoses seen in family practices should be taken into account when planning PBRN studies. The results have implications for practice resource planning as well.

Several studies in this issue advance the methods for conducting PBRN research. These include an assessment of the computerized data collection capabilities of a well-established pediatric PBRN ${ }^{5}$ and a study of the feasibility of using of pen-tablet computers to engage patients in collecting data in a PBRN. ${ }^{6}$ A study by the Kentucky Ambulatory Network shows how using the methods of the National Ambulatory Care Survey can help to establish the representativeness of a new PBRN while beginning the study of topics relevant to participating clinicians. ${ }^{7}$ The unique challenges and opportunities of conducting cross-national PBRN research are described by Green and colleagues. ${ }^{8}$ Their international study of acute otitis media took advantage of the natural experiment of different approaches to treatment in North America, Great Britain, and the Netherlands.

An important methodological study in the PBRN theme issue examines the potential of PBRNs for rapid ascertainment of bioterrorism. ${ }^{9} \mathrm{~A}$ related study ${ }^{10}$ in this issue shows the difficulty of relying only on diagnostic codes for surveillance for inhalational anthrax outbreaks.

\section{THE PATIENT-CLINICIAN RELATIONSHIP}

As highlighted in the editorial by Moira Stewart, $\mathrm{PhD}$, another cluster of articles in this issue provides rich new insights into the importance of continuity of care and 
new ways of conceptualizing and acting on the physician-patient relationship. ${ }^{11-16}$ These studies provide a strong impetus for practicing and designing health care systems in a way that fosters healing relationships. At the same time, they highlight the need for additional research and point toward new hypotheses. Each of these articles advances the field and adds a fresh perspective.

\section{EPIDEMIOLOGY AND METHODOLOGY}

The study by Fiscella and colleagues ${ }^{17}$ discovers that years of schooling is a potent risk factor for coronary heart disease mortality. This prospective examination of a large, nationally representative sample of adults shows that low education level is a risk factor of the same order of magnitude as smoking, elevated cholesterol levels, and elevated systolic blood pressure. This knowledge can be used to guide the aggressiveness of treatment of other, mutable risk factors.

An analysis of young adults participating in a randomized clinical trial of a brief alcohol use reduction intervention ${ }^{18}$ results in long-term reductions in high-risk drinking, as well as reductions in the important outcomes of motor vehicle crashes, arrests for substance or liquor violations, and emergency department visits.

Jerant and colleagues also used a large, nationally representative sample to examine age-related disparities in cancer-screening interventions. ${ }^{19}$ The overuse and underuse of different services is a wake-up call for better targeting of resources.

Two methodology studies give us a new and validated instrument for assessing the spirituality of wellbeing $^{20}$ and for planning complex research projects in community settings. ${ }^{21}$

A study of North Carolina Medicaid enrollees finds that drug expenditures are driven by increases in the number of prescriptions for new and more expensive medications. ${ }^{22} \mathrm{~A}$ possible solution to rising prescription costs is presented in an intervention study in an integrated system of primary care practices. In this setting, an electronic decision support system shifted prescribing toward more evidence-based care and can decrease prescription costs. ${ }^{23}$

We encourage readers to share questions, interpretations, and exhortations ${ }^{24}$ at http://www.annfammed.org.

\section{References}

1. Mold JW, Roberts M, Aboshady HM. Prevalence and predictors of night sweats, day sweats, and hot flashes in older primary care patients: an OKPRN study. Ann Fam Med. 2004;2:391-397.

2. Vinson DC. Comfortably engaging: which approach to alcohol screening should we use? Ann Fam Med. 2004;2:398-404.
3. Beasley JW, Hankey TH, Erickson R, et al. How many problems do family physicians manage at each encounter? A WReN study. Ann Fam Med. 2004;2:405-410.

4. Pace WD, Dickinson LM, Staton EW. Seasonal variation in diagnoses and visits to family physicians. Ann Fam Med. 2004;2:411-417.

5. Ariza AJ, Binns HJ, Christoffel KK. Evaluating computer capabilities in a primary care practice-based research network. Ann Fam Med. 2004;2:418-420.

6. Main DS, Quintela J, Araya-Guerra R, Holcomb S, Pace WD. Exploring patient reactions to pen-tablet computers: a report from CaReNet. Ann Fam Med. 2004;2:421-424.

7. Pearce KA, Love MM, Barron MA, Matheny SC, Mahfoud Z. How and why to study the practice content of a practice-based research network. Ann Fam Med. 2004;2:425-428.

8. Green LA, Fryer GE Jr, Froom P, Culpepper L, Froom J. Opportunities, challenges, and lessons of international research in practicebased research networks: the case of an international study of acute otitis media. Ann Fam Med. 2004;2:429-433.

9. Temte JL, Anderson AL. Rapid assessment of agents of biological terrorism: defining the primary care differential diagnosis of inhalational anthrax using electronic communication in a practice-based research network. Ann Fam Med. 2004;2:434-437.

10. Temte JL, Zinkel AR. The primary care differential diagnosis of inhalational anthrax. Ann Fam Med. 2004;2:438-444.

11. Saultz J, Albedaiwi W. Interpersonal continuity of care and patient satisfaction: a critical review. Ann Fam Med. 2004;2:445-451.

12. Mainous AG III, Goodwin MA, Stange KC. Patient-physician shared experiences and value patients place on continuity of care. Ann Fam Med. 2004;2:452-454.

13. Kerse N, Buetow S, Mainous AG III, Young G, Coster G, Arroll B. Physician-patient relationship and compliance with medication: a primary care investigation. Ann Fam Med. 2004;2:455-461.

14. Schers $H$, van de Ven $C$, van den Hoogen $H$, Grol $R$, van den Bosch W. Patients' needs for contact with their GP at the time of hospital admission and other life events: a quantitative and qualitative exploration. Ann Fam Med. 2004;2:462-468.

15. Buetow SA. Towards a new understanding of provider continuity. Ann Fam Med. 2004;2:509-511.

16. Justin RG. Linking Ruth to her past. Ann Fam Med. 2004;2:512-513.

17. Fiscella $K$, Franks P. Should years of schooling be used to guide treatment of coronary risk factors? Ann Fam Med. 2004;2:469-473.

18. Grossberg PM, Brown DD, Fleming MF. Brief physician advice for highrisk drinking among young adults. Ann Fam Med. 2004;2:474-480.

19. Jerant AF, Franks $P$, Jackson JE, Doescher MP. Age-related disparities in cancer screening: analysis of 2001 behavioral risk-factor surveillance system data. Ann Fam Med. 2004;2:481-487.

20. Daaleman TP, Frey BB. The Spirituality Index of Well-Being: a new instrument for health-related quality of life research. Ann Fam Med. 2004;2:499-503.

21. Zayas LH, McKee DM, Jankowski KR. Adapting psychosocial intervention research to urban primary care environments: a case example. Ann Fam Med. 2004;2:504-508.

22. Fink KS, Byrns PJ. Changing prescribing patterns and increasing prescription expenditures in Medicaid. Ann Fam Med. 2004;2:488-493.

23. McMullin ST, Lonergan TP, Rynearson CS, Doerr TD, Veregge PA, Scanlan ES. Impact of an evidence-based computerized decision support system on primary care prescription costs. Ann Fam Med. 2004;2:494-498.

24. Stange KC. On TRACK: questions, interpretation, exhortation. Ann Fam Med. 2004;2:514-517. 